\title{
A Double-Walled Incubator Alters the Partition of Body Heat Loss of Premature Infants
}

\author{
EDWARD F. BELL ${ }^{(40)}$ AND GLADYS R. RIOS \\ Department of Pediatrics, University of Iowa College of Medicine, Iowa City, Iowa, USA
}

\begin{abstract}
Summary
Partitional calorimetry was used to assess the influence of a double-walled incubator (Air-Shields C-86 Isolette) on the body heat loss of eight premature newborn infants (birth weights 1.44$1.89 \mathrm{~kg}$, ages 6-19 days). Each infant was studied in the same incubator with and without the inner wall. Incubator heater output was regulated by servocontrol to maintain the abdominal skin temperature at $36.5^{\circ} \mathrm{C}$. Operative environmental temperature was the same (mean $33.0^{\circ} \mathrm{C}$ ) in both incubators. There were no differences in body temperatures, oxygen consumption, carbon dioxide production, respiratory quotient, or evaporative water and heat losses. The double-walled incubator reduced radiant heat loss but increased convective heat loss, so that the total rate of body heat loss was unchanged.
\end{abstract}

Low-birth-weight infants are commonly cared for in incubators that are warmed by the circulation of heated air. The temperature of the air in the incubator, which determines convective heat loss from the infant's body, responds quickly to changes in the output of the heater. The temperature of the incubator walls, which determines radiant heat loss, is influenced by the temperatures of the air and walls of the nursery as well as the incubator air. Because nurseries are air-conditioned for the comfort of the staff, a small infant loses considerable heat by radiation to the relatively cool inner surfaces of the incubator, even though the air temperature in the incubator may be quite close to body temperature (16).

In an attempt to reduce radiant heat loss by infants in incubators, several manufacturers have introduced incubators with walls made of two layers of Plexiglas separated by a layer of air several centimeters thick. The inner surface of the inner wall should be warmer and less responsive to changes in ambient nursery temperatures, thus reducing the infant's heat loss by radiation. The purpose of this study was to examine the influence of a double walled incubator on the body heat loss of premature infants, when the incubator heater was regulated by thermostatic or servocontrol to maintain a constant abdominal skin temperature.

\section{METHODS}

Subjects. The study was approved by the Human Subjects Review Committee of the University of Iowa. Informed consent was obtained from the parents of each subject. The eight subjects had birth weights from $1.44-1.89 \mathrm{~kg}$ (median $1.54 \mathrm{~kg}$ ) and gestational ages from 30-35 wk (median $32 \mathrm{wk}$ ). All had birth weights between the tenth and ninetieth percentiles for gestational age. The postnatal ages at the time of study ranged from 6-19 days (median 13.5 days). All subjects had begun to gain weight; the median study weight was $1.60 \mathrm{~kg}$. None required intravenous fluids, supplementary oxygen or ventilatory assistance at the time of study.

Study design. All studies were performed in a quiet, temperature-controlled room adjacent to the nursery. Each infant was studied in both single and double-walled incubators during con- secutive periods on the same day. The order in which each infant was studied in the two incubators was assigned so that four infants were studied first in each incubator. The double-walled incubator was the Double Wall Model C-86 Isolette (Air-Shields, Inc., Hatboro, PA) (33), which is warmed by the forced convection of heated air. The single-walled incubator was the same incubator without the $3-\mathrm{mm}$ Plexiglas inner wall. In both single and doublewalled incubators the heater output was regulated by servocontrol to maintain the infant's abdominal skin temperature at $36.5^{\circ} \mathrm{C}$.

Before each study, the incubator was kept overnight at a constant air temperature predicted to be thermoneutral based on the subject's birth weight and postnatal age (1). The air temperature was maintained using the incubator's servocontrol system with the patient probe suspended $10 \mathrm{~cm}$ below the center of the top surface of the incubator's Plexiglas hood. The Potter Baby Scale used to measure insensible water loss was also placed into the incubator the day before each study. On the morning of the study, the infant was placed into the warm incubator (single or double-walled) at about 0800 . All infants were placed supine on a diaper covering the load plate of the Potter Baby Scale. Infants were naked except for a plastic-lined disposable diaper that was securely applied to prevent evaporation of urine. The patient probe was taped to the abdomen, midway between the xiphoid and the umbilicus, with the servocontrol set point at $36.5^{\circ} \mathrm{C}$. After a wait of $1-3 \mathrm{~h}$, body and incubator temperatures had stabilized. If rectal temperature exceeded $37.3^{\circ} \mathrm{C}$ during this equilibrium period, the servocontrol set point was lowered to $36.0^{\circ} \mathrm{C}$. The infant was fed milk or formula by gavage through an indwelling orogastric or nasogastric tube. The milk or formula was warmed by placing it into the incubator for $1 \mathrm{~h}$ before feeding. One $\mathrm{h}$ after feeding, the first $2-\mathrm{h}$ measurement period was begun.

After the measurements (described below) were completed, the inner wall was added or removed quickly without moving the infant from the incubator. When incubator air and wall temperatures were again stable ( $1 / 2$ to $1 \mathrm{~h}$ ), the infant was fed again (with warm milk or formula), and the second measurement period was begun $1 \mathrm{~h}$ after feeding. During both 2 -h measurement periods, all measurements were recorded at 15 -min intervals except respiratory gas exchange (oxygen consumption and carbon dioxide production), which was continuously recorded.

Environmental measurements. Barometric pressure was recorded from an aneroid barometer. Relative humidity inside the incubator hood was determined from wet bulb and dry bulb temperatures. The electrical power consumed by the incubator was measured with a watt-hour meter (Ohio Semitronics, Inc., Model EM-5, Columbus, $\mathrm{OH}$ ). Power consumption in watt-hours was divided by the measurement duration in $\mathrm{h}$, and expressed as watts. The power used by the air circulation fan and indicator lights (measured with heater off) was $10 \mathrm{~W}$. This figure was subtracted from the mean power consumed by the incubator during an entire 2-h measurement period to produce the mean power consumed by the incubator heater. The infant's heart rate and respiratory rate were continuously monitored and recorded at 15 -min intervals. The infant's level of activity was graded every $15 \mathrm{~min}$ on the ten-point scale of Brück et al. (5), from -4 (eyes closed, no movement) to +5 (crying). 
Temperature measurements were performed with thermistor probes (Yellow Springs Instruments, Series 400 probes, Yellow Springs, $\mathrm{OH}$ ) attached to two twelve-channel switch boxes (YSI \#4002) and a digital telethermometer (YSI \#49TA). Each probe had been tested with a certified mercury thermometer (U.S. National Bureau of Standards) in a water bath. Sixteen of 18 thermistor probes used in this study agreed with the certified thermometer within $0.1^{\circ} \mathrm{C}$ throughout the range tested $\left(20-40^{\circ} \mathrm{C}\right.$ for environmental probes, $30-40^{\circ} \mathrm{C}$ for body probes). Correction equations were determined for the other two probes and applied to all measurements performed with these probes.

The following environmental temperatures were measured and recorded every $15 \mathrm{~min}$ : room air; incubator air $(10 \mathrm{~cm}$ below the center hole in the top of the incubator); inner Plexiglas wall of the head hood used for gas exchange measurements; gas entering and leaving the head hood; gas entering the flow meter (used for STPD correction); inner surfaces of the left (cephalad) (LW) and right (caudad) (RW) end walls of the incubator hood, which consist of single-layer Plexiglas; inner surfaces of the front (FIW), top (TIW), and rear (RIW) inner walls; and inner surfaces of the front (FOW), top (TOW), and rear (ROW) outer walls. The mean inner wall temperature $\left(\overline{\mathrm{T}}_{\text {wall }}\right)$ was calculated as the weighted average of the six inner wall temperatures, substituting the temperature of the head hood wall (HW) for the left incubator wall:

$\overline{\mathrm{T}}_{\text {wall }}=0.22 \mathrm{~T}_{\mathrm{HW}}+0.22 \mathrm{~T}_{\mathrm{FiW}}+0.22 \mathrm{~T}_{\mathrm{TrW}}+0.22 \mathrm{~T}_{\mathrm{RIW}}+0.11 \mathrm{~T}_{\mathrm{RW}}$

The operative environmental temperature is a weighted average of mean radiant (or wall) temperature and air temperature. It describes in a single expression the thermal properties of the physical environment that determine radiant and convective heat loss. Its difference from mean skin temperature is directly proportional to the sum of nonevaporative heat losses (31). Operative temperature $\left(\mathrm{T}_{\mathrm{op}}\right)$ was calculated assuming a 6:4 partition of radiant to convective heat losses (16):

$$
\mathrm{T}_{\text {op }}=0.6 \overline{\mathbf{T}}_{\text {wall }}+0.4 \mathrm{~T}_{\text {air }}
$$

Body temperatures. Abdominal skin temperature was measured with a thermistor probe taped to the mid-epigastrium, beside but not touching the servocontrol probe. Cheek skin temperature was monitored to assure that facial temperature was not changing sufficiently to alter the rate of oxygen consumption (24). Heel skin temperature was monitored with a probe taped to the heel pad. Rectal temperature was measured with a soft, flexible vinyl-covered probe (YSI \#402) inserted $5 \mathrm{~cm}$ beyond the anus (18).

Mean skin temperature $\left(\overline{\mathrm{T}}_{s}\right)$ was calculated as the weighted average of abdominal $\left(\mathrm{T}_{\mathrm{abd}}\right)$, cheek $\left(\mathrm{T}_{\text {cheek }}\right)$, and heel $\left(\mathrm{T}_{\text {heel }}\right)$ temperatures (26) assuming the abdominal temperature to be representative of the entire trunk and upper limbs, cheek to be representative of the entire head, and heel to represent hands and feet:

$$
\overline{\mathbf{T}}_{\mathrm{s}}=0.67 \mathrm{~T}_{\mathrm{abd}}+0.23 \mathrm{~T}_{\text {cheek }}+0.10 \mathrm{~T}_{\text {heel }}
$$

Gas exchange. The rates of oxygen consumption and carbon dioxide production were measured by an open-circuit technique with several modifications from the system described previously (2). A Plexiglas hood was placed over the infant's head (Fig. 1). The top of the head hood was replaced with thin $\left(1.3 \times 10^{-5} \mathrm{~m}\right)$, clear polyethylene film (Glad Wrap, Union Carbide Corp., New York, NY) to reduce the effects of the hood on radiant heat exchange from the head. The hood was airtight except for the. exhaust hose and the neck opening, which was adjusted according to the size of the infant. A mixture of incubator air and expired gas was drawn from the head hood at a constant rate of 3 liters/ min per $\mathrm{kg}$ body weight. This sample gas was passed through a drying column, and temperature and flow rate were measured. Then the gas was pumped into a paramagnetic oxygen analyzer (Servomex OA540, Taylor Instrument Co., Rochester, NY) and an infrared carbon dioxide analyzer (Beckman LB2, Schiller Park, IL). The system was made with Tygon tubing and glass connectors and stopcocks.

Incubator air was analyzed at the beginning and end of each measurement period by switching the two stopcocks to the positions shown in the inset in Figure 1. While incubator air was being analyzed, gas was still being drawn from the head hood by an exhaust pump (Fig. 1) also set to draw 3 liters/min per $\mathrm{kg}$. When the sample gas from the hood was being delivered through the system to the gas analyzers, the exhaust pump withdrew incubator air simultaneously. This arrangement allowed the head hood to be exhausted continuously, preventing the accumulation of carbon dioxide while maintaining the same air flow dynamics in the incubator at all times, with a total of 6 liters/min per $\mathrm{kg}$ being withdrawn. Thus, the intake of outside air into the incubator was presumably greater than the usual intake of 35 liters $/ \mathrm{min}$.

The oxygen and carbon dioxide analyzers were calibrated before each measurement period with pure nitrogen and a calibration gas of known composition, approximately $21 \%$ oxygen and $0.8 \%$ carbon dioxide, analyzed with a Haldane apparatus. The calibration gases were drawn through the entire system with the hose that was used to sample incubator air. In the earlier studies, flow was controlled with a needle valve and measured with a rotameter (Fischer \& Porter, Model 10A3555S, Warminster, PA). More recently, flow has been regulated and measured with an electronic flow controller and flowmeter (Matheson, Mass Flow Controller \#8240-0414, Lyndhurst, NJ). Both the rotameter and the mass flowmeter were calibrated with a 120-liter spirometer (Warren E. Collins, Inc., Chain-Compensated Gasometer, Braintree, MA). The oxygen and carbon dioxide analyzers were attached to integrating recorders (Linear Instruments Corp., Model 252, Irvine, CA). The oxygen and carbon dioxide concentrations were continuously recorded and integrated. The mean concentrations of oxygen $\left(\mathrm{FsO}_{2}\right)$ and carbon dioxide $\left(\mathrm{FSCO}_{2}\right)$ in the gas drawn from the hood were used to calculate the respiratory quotient (RQ) and the mean rates of oxygen consumption and carbon dioxide production during each 2-hour measurement period. Mean oxygen consumption $\left(\mathrm{V}_{2}\right)$ and carbon dioxide production $\left(\dot{\mathrm{V}} \mathrm{CO}_{2}\right)$ rates were calculated as the product of flow rate $(\dot{Q})$ and the difference in gas concentration between the incubator air and the mixed expired gas sample, correcting for the difference between inspired and expired volumes due to the fact that $\dot{\mathrm{VO}}_{2}$ and $\dot{\mathrm{VCO}}_{2}$ are seldom equal (20). Mean RQ was calculated first and then used to calculate $\dot{\mathrm{VO}}_{2}$ and $\dot{\mathrm{V}} \mathrm{CO}_{2}$ :

$$
\mathrm{RQ}=\frac{\left(\mathrm{FsCO}_{2}-\mathrm{FiCO}_{2}\right)\left(1-\mathrm{FiO}_{2}\right)-\left(\mathrm{FiO}_{2}-\mathrm{FsO}_{2}\right)\left(\mathrm{FiCO}_{2}\right)}{\left(\mathrm{FiO}_{2}-\mathrm{FsO}_{2}\right)\left(1-\mathrm{FiCO}_{2}\right)-\left(\mathrm{FsCO}_{2}-\mathrm{FiCO}_{2}\right)\left(\mathrm{FiO}_{2}\right)}
$$

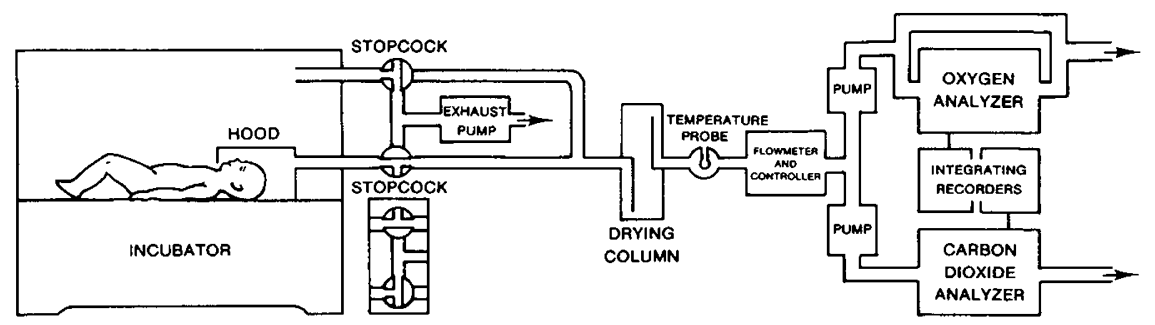

Fig. 1. Open circuit system for measuring oxygen consumption and carbon dioxide production. A mixture of ambient air and expired gas is drawn from the head hood at a constant and precisely measured flow rate and analyzed continuously for oxygen and carbon dioxide concentration. Ambient incubator air is sampled at the beginning and end of each measurement period by switching the stopcocks to the positions shown in the inset. The incubator is viewed here from the rear. The infant's head is usually to the left when facing the front of the incubator, where the access door is located. 
where $\mathrm{FsCO}_{2}$ and $\mathrm{FiCO}_{2}$ are the mean fractional concentrations of carbon dioxide in the mixed expired (sample) gas and the inspired gas (incubator air), respectively, and $\mathrm{FiO}_{2}$ and $\mathrm{FsO}_{2}$ are the mean fractional oxygen concentrations in the inspired and sample gases, respectively. The equations used to calculate $\mathrm{V}_{2}$ and $\dot{\mathrm{V}} \mathrm{CO}_{2}$ were:

$$
\dot{\mathrm{V}} \mathrm{O}_{2}=\frac{\dot{\mathrm{Q}}\left(\mathrm{FiO}_{2}-\mathrm{FsO}_{2}\right)}{1-\left(\mathrm{FiO}_{2}\right)(1-\mathrm{RQ})}
$$

and

$$
\dot{\mathrm{V} C O}{ }_{2}=\frac{\dot{\mathrm{Q}}\left(\mathrm{FsCO}_{2}-\mathrm{FiCO}_{2}\right)}{1+\left(\mathrm{FiCO}_{2}\right)(1-\mathrm{RQ}) / \mathrm{RQ}}
$$

Mean oxygen consumption and carbon dioxide production were corrected to standard temperature and pressure, dry, and expressed as $\mathrm{ml} / \mathrm{kg}$ body weight per $\min \left(\mathrm{ml} \cdot \mathrm{kg}^{-1} \cdot \mathrm{min}^{-1}\right)$.

Insensible water loss. Body weight loss was continuously monitored with a Potter Baby Scale (James Addison Potter, Model no. 62, West Hartford, CT), an electronic scale with a resolution of $0.5 \mathrm{~g}$. Care was taken to allow sufficient time for thermal equilibration prior to each measurement period $(8,10)$. Insensible water loss (IWL, $\mathrm{g} \cdot \mathrm{kg}^{-1} \cdot \mathrm{h}^{-1}$ ) was calculated by subtracting the difference in weight between the carbon dioxide produced and the oxygen consumed from the total weight loss in a measurement period $\left(\Delta \mathrm{wt}, \mathrm{g} \cdot \mathrm{kg}^{-1} \cdot \mathrm{h}^{-1}\right)(17)$ :

$$
\mathrm{IWL}=\Delta \mathrm{wt}-\left(0.1179 \dot{\mathrm{VCO}}_{2}-0.0857 \dot{\mathrm{VO}}_{2}\right)
$$

Heat exchange calculations. The heat exchange between the body and its surroundings adheres to the First Law of Thermodynamics and is expressed by the "body heat balance equation" (3): $M=E+R+C+K+W+S$, where $M$ is metabolic free energy production (metabolic heat production plus work against external forces, $W) ; E$ is heat loss by evaporation; $R$ is heat loss by radiation; $C$ is heat loss by convection; $K$ is heat loss by conduction; and $S$ is heat stored in the body (+ for gain, - for loss). Conductive heat loss is a very small and nearly constant portion of total heat loss in both adults $(7,11,14)$ and newborn infants $(15,16)$, and has been included with convection $(C)$ in the calculations of the partition of heat loss. The subjects were assumed to perform no work against external forces, thus reducing the body heat balance equation to: $M=E+R+C+S$, where $M$ now represents metabolic heat production. The measurements of body and environmental temperatures, gas exchange and insensible water loss thus allowed estimation of each of the factors in the above equation.

Metabolic heat production $(M)$ was calculated from the mean oxygen consumption ( $\left(\mathrm{VO}_{2}\right)$ and $\mathrm{RQ}$, according to the equation of Lusk (21): $M=\dot{\mathrm{VO}}_{2}[(1.232 \mathrm{RQ}+3.815) \mathrm{kcal} / \mathrm{liter}]$. Nitrogen elimination was not measured, because neglecting protein metabolism has little effect on the calculation of heat production from gas exchange using the method of Lusk $(21,34)$.

Evaporative heat loss $(E)$ was calculated as the product of insensible water loss (IWL) and the heat of evaporation of water, $0.580 \mathrm{kcal} / \mathrm{g}(28): E=\mathrm{IWL} \times 0.580 \mathrm{kcal} / \mathrm{g}$.

Radiant heat loss $(R)$ was calculated from the Stefan-Boltzmann Law (14):

$$
R=\sigma \cdot \epsilon_{\mathrm{s}} \cdot \epsilon_{\mathrm{wall}} \cdot\left(\overline{\mathrm{T}}_{\mathrm{s}}^{4}-\overline{\mathrm{T}}_{\text {wall }}{ }^{4}\right) \cdot \mathrm{A} \cdot \mathrm{f} \cdot(\mathrm{wt})^{-1}
$$

where $\sigma$ is the universal radiation constant, $4.93 \times 10^{-8} \mathrm{kcal} \cdot \mathrm{h}^{-1}$. $\mathrm{m}^{-2} \cdot{ }^{\circ} \mathrm{K}^{-4} ; \epsilon_{\mathrm{s}}$ is the emissivity of the skin [assumed to be 1, i.e., a perfect "black body" (13)]; $\epsilon_{\text {wall }}$ is the emissivity of the inner walls of the incubator [assumed to be $0.97(12)] ; \overrightarrow{\mathrm{T}}_{s}$ and $\overline{\mathrm{T}}_{\text {wall }}$ are the mean absolute skin and wall temperatures $\left({ }^{\circ} \mathrm{K}\right)$; $\mathrm{A}$ is the body surface area; $f$ is the ratio of the effective radiating surface area to the total area; and wt is the body weight. The incubator walls were assumed to be opaque to the wavelengths of energy radiated from the infant's body (16). Body surface area was calculated from body weight using Meeh's formula $(23,27): \mathrm{A}=\mathrm{k}(\mathrm{wt})^{2 / 3}$, with a constant $\mathrm{k}$ of $0.103 \mathrm{~m}^{2} \cdot \mathrm{kg}^{-2 / 3}(19)$. The effective radiating surface area of naked adults has been estimated at $0.74-0.78$ when seated (30) or standing at attention (14), and may be altered considerably by changes in stance. One subject of Bohnenkamp and Pasquay (4) reduced his effective radiating area to 0.25 by assuming a tight crouch. Because there is no information available on the effective radiating surface area of newborn infants, a value of 0.50 was assumed for our subjects, who were lying supine on an insulated surface. Substituting the values for $\sigma, \epsilon_{\mathrm{s}}, \epsilon_{\text {wall }}, \mathrm{A}$, and $\mathrm{f}$ into the above equation for the Stefan-Boltzmann Law produced this simplified form:

$$
R=2.46 \times 10^{-9} \mathrm{kcal} \cdot \mathrm{kg}^{-2 / 3} \cdot \mathrm{h}^{-1} \cdot{ }^{\circ} \mathrm{K}^{-4} \cdot\left(\overline{\mathrm{T}}_{\mathrm{s}}^{4}-\overline{\mathrm{T}}_{\text {wall }}{ }^{4}\right) \cdot(\mathrm{wt})^{-1 / 3}
$$

Convective heat loss $(C)$ depends on the temperature gradient between the skin $\left(\bar{T}_{s}\right)$ and the ambient air $\left(\mathrm{T}_{\text {air }}\right)$ and the air velocity (v):

$$
C=\left(\mathrm{a}+\mathrm{b} \cdot \mathrm{v}^{\mathrm{n}}\right)\left(\overline{\mathrm{T}}_{\mathrm{s}}-\mathrm{T}_{\mathrm{air}}\right)
$$

where $a$ is the coefficient for free convection and $b \cdot v^{n}$ is the coefficient for forced convection (7). Because these coefficients are not known for young infants and are quite difficult to determine experimentally (29), convective heat loss was calculated by difference: $C=M-E-R-S$. As mentioned earlier, $C$ includes heat loss by conduction as well as convection. The main stream of heated air in the Isolette C-86 incubator comes from below the infant compartment, is directed upward along the inside of the left wall, passes from left to right along the upper part of the infant compartment, and returns to the heater and fan at the right end of the mattress. Very little moving air passes adjacent to the infant's body. Air velocity was measured with a hot-wire anemometer (Alnor 8500 , Niles, IL) $6 \mathrm{~cm}$ above the center of the mattress. In both single and double-walled incubators the air velocity was below $0.05 \mathrm{~m} / \mathrm{sec}$, the limit of sensitivity of the anemometer. By assuming the heat loss due to forced convection to be negligible, and disregarding the small conductive heat loss included in $C$, the convection coefficient (a) could be calculated for our subjects in the single and double-walled incubators:

$$
\mathrm{a}=C /\left(\overline{\mathrm{T}}_{\mathrm{s}}-\mathrm{T}_{\text {air }}\right)
$$

Heat storage $(S)$ was calculated from changes in body temperature, assuming the specific heat of the body to be $0.84 \mathrm{kcal} \cdot \mathrm{kg}^{-1}$. ${ }^{\circ} \mathrm{C}^{-1}(25)$ :

$$
S=0.84 \mathrm{kcal} \cdot \mathrm{kg}^{-1} \cdot{ }^{\circ} \mathrm{C}^{-1} \cdot\left(0.6 \Delta \mathrm{T}_{\text {rect }}+0.4 \Delta \overline{\mathrm{T}}_{\mathrm{s}}\right) / \Delta t
$$

where $\Delta T_{\text {rect }}$ is the difference between final and initial rectal temperature, $\Delta \overline{\mathrm{T}}_{\mathrm{s}}$ is the difference between final and initial mean skin temperature, and $\Delta t$ is the duration of the measurement period (in hours). The mean temperature of all body tissues was assumed to be $60 \%$ of the rectal temperature plus $40 \%$ of the mean skin temperature (6). Heat storage is positive when body temperature rises and heat is gained by the body.

Statistical analysis. All measured or derived results were compared between single and double-walled incubators using the $t$ test for paired observations. Differences were defined as statistically significant when $P$ (two-tailed) was less than 0.05 .

\section{RESULTS}

The mean room temperature was $24.0^{\circ} \mathrm{C}$ (S.D. 2.7) for the single-walled incubator and $24.0^{\circ} \mathrm{C}$ (S.D. 2.4) for the doublewalled incubator. The mean relative humidity in the single-walled incubator was $26 \%$ (S.D. 6); in the double-walled incubator it was $25 \%$ (S.D. 6). Mean infant heart rate and respiratory rate did not differ between the two incubators. The portion of time spent with activity score of 0 or less ranged from $88-100 \%$ (mean 97, median 100 ) in the single-walled incubator and from 67-100\% (mean 92 , median 100) in the double-walled incubator.

The other results are summarized in Table 1 . There were no significant differences in any of the body temperatures. The incubator air temperature was lower with the double wall (mean $33.8^{\circ} \mathrm{C}$, S.D. 1.7) than with the single wall (mean $34.8^{\circ} \mathrm{C}$, S.D. 2.1 ), whereas the mean wall temperature was higher with the double wall (mean $32.3^{\circ} \mathrm{C}$, S.D. 1.2) than the single wall (mean $31.7^{\circ} \mathrm{C}$, S.D. 1.1). Operative environmental temperature was 
Table 1. Heat exchange data for premature infants in single and double-walled incubators ${ }^{1}$

\begin{tabular}{|c|c|c|c|c|c|c|c|c|c|c|c|c|c|c|c|c|c|c|}
\hline \multirow[b]{2}{*}{ Subject } & \multirow[b]{2}{*}{ Incubator } & \multicolumn{6}{|c|}{$\begin{array}{l}\text { Temperatures } \\
\left({ }^{\circ} \mathrm{C}\right)\end{array}$} & \multirow{2}{*}{$\begin{array}{l}\text { Power used by } \\
\text { heater } \\
\text { (W) }\end{array}$} & \multicolumn{3}{|c|}{$\begin{array}{l}\text { Gas exchange } \\
\left(\mathrm{ml} \cdot \mathrm{kg}^{-1} \cdot \mathrm{min}^{-1}\right)\end{array}$} & \multirow{2}{*}{$\begin{array}{c}\text { Insen- } \\
\text { sible } \\
\text { water } \\
\text { loss } \\
\left(\mathrm{g} \cdot \mathrm{kg}^{-1} \cdot \mathrm{h}^{-1}\right) \\
\end{array}$} & \multicolumn{6}{|c|}{$\begin{array}{l}\text { Heat production and loss } \\
\left(\mathrm{kcal} \cdot \mathrm{kg}^{-1} \cdot \mathrm{h}^{-1}\right)\end{array}$} \\
\hline & & $\mathrm{T}_{\mathrm{ahd}}$ & $\overline{\mathrm{T}}_{\mathrm{s}}$ & $\mathrm{T}_{\text {rect }}$ & $\mathrm{T}_{\text {air }}$ & $\overline{\mathrm{T}}_{\text {wall }}$ & $T_{\mathrm{op}}$ & & $\dot{\mathrm{VO}}_{2}$ & $\dot{\mathrm{V}} \mathrm{CO}_{2}$ & $\mathrm{RQ}$ & & $M$ & $S$ & $M-S$ & $E$ & $R$ & $C$ \\
\hline \multirow[t]{2}{*}{1} & Single & 36.5 & 36.4 & 37.3 & 34.4 & 30.3 & 31.9 & 68 & 9.03 & 7.99 & 0.88 & 1.41 & 2.66 & -0.08 & 2.74 & 0.82 & 1.37 & 0.55 \\
\hline & Double & 36.5 & 36.4 & 37.3 & 34.1 & 31.8 & 32.7 & 86 & 10.43 & 8.08 & 0.77 & 1.58 & 2.98 & 0 & 2.98 & 0.92 & 1.04 & 1.02 \\
\hline \multirow[t]{2}{*}{2} & Single & 36.5 & 36.5 & 37.1 & 36.4 & 32.7 & 34.2 & 108 & 7.60 & 5.72 & 0.75 & 1.58 & 2.16 & 0.08 & 2.08 & 0.92 & 0.94 & 0.22 \\
\hline & Double & 36.4 & 36.5 & 37.3 & 35.1 & 33.1 & 33.9 & 99 & 8.20 & 6.56 & 0.80 & 1.56 & 2.36 & -0.06 & 2.42 & 0.91 & 0.84 & 0.67 \\
\hline \multirow[t]{2}{*}{3} & Single & 36.4 & 36.4 & 37.1 & 35.5 & 31.5 & 33.5 & 106 & 7.80 & 7.32 & 0.94 & 0.92 & 2.33 & -0.06 & 2.39 & 0.53 & 1.21 & 0.65 \\
\hline & Double & 36.5 & 36.3 & 37.1 & 34.0 & 31.8 & 33.7 & 90 & 7.61 & 8.11 & 1.07 & 0.86 & 2.34 & -0.08 & 2.42 & 0.50 & 1.12 & 0.80 \\
\hline \multirow[t]{2}{*}{4} & Single & 36.5 & 36.3 & 37.3 & 35.5 & 32.7 & 33.8 & 76 & 6.03 & 5.60 & 0.93 & 1.05 & 1.79 & -0.06 & 1.85 & 0.61 & 0.90 & 0.34 \\
\hline & Double & 36.5 & 36.3 & 37.2 & 34.8 & 33.7 & 34.1 & 61 & 5.92 & 5.23 & 0.88 & 1.05 & 1.74 & 0 & 1.74 & 0.61 & 0.66 & 0.47 \\
\hline \multirow[t]{2}{*}{5} & Single & 36.4 & 36.1 & 37.3 & 34.3 & 31.8 & 32.8 & 46 & 8.06 & 7.31 & 0.91 & 1.06 & 2.39 & 0.11 & 2.28 & 0.61 & 1.04 & 0.63 \\
\hline & Double & 35.7 & 35.5 & 37.4 & 32.4 & 31.4 & 31.8 & 64 & 8.14 & 7.49 & 0.92 & 1.04 & 2.42 & -0.17 & 2.59 & 0.60 & 0.98 & 1.01 \\
\hline \multirow[t]{2}{*}{6} & Single & 36.4 & 36.5 & 37.0 & 37.4 & 32.7 & 34.6 & 111 & 6.83 & 6.46 & 0.95 & 2.14 & 2.04 & 0.10 & 1.94 & 1.24 & 0.97 & -0.27 \\
\hline & Double & 36.5 & 36.5 & 37.0 & 36.1 & 33.7 & 34.7 & 92 & 6.53 & 6.02 & 0.92 & 1.53 & 1.94 & 0.05 & 1.89 & 0.89 & 0.72 & 0.28 \\
\hline \multirow[t]{2}{*}{7} & Single & 36.3 & 36.3 & 37.1 & 34.5 & 31.6 & 32.8 & 80 & 8.68 & 8.40 & 0.97 & 1.52 & 2.61 & -0.04 & 2.65 & 0.88 & 1.12 & 0.65 \\
\hline & Double & 36.4 & 36.4 & 37.1 & 33.8 & 32.2 & 32.8 & 67 & 9.43 & 8.81 & 0.93 & 1.68 & 2.81 & 0.07 & 2.74 & 0.97 & 1.01 & 0.76 \\
\hline \multirow[t]{2}{*}{8} & Single & 35.9 & 35.7 & 37.3 & 30.2 & 30.0 & 30.1 & 3 & 9.59 & 9.84 & 1.03 & 0.84 & 2.92 & -0.11 & 3.03 & 0.49 & 1.27 & 1.27 \\
\hline & Double & 36.1 & 36.0 & 37.3 & 30.5 & 30.4 & 30.4 & 4 & 10.92 & 10.86 & 0.99 & 1.00 & 3.30 & -0.11 & 3.41 & 0.58 & 1.25 & 1.58 \\
\hline \multirow[t]{2}{*}{ Mean } & Single & 36.4 & 36.3 & 37.2 & 34.8 & 31.7 & 33.0 & 75 & 7.95 & 7.33 & 0.92 & 1.32 & 2.36 & -0.01 & 2.37 & 0.76 & 1.10 & 0.51 \\
\hline & Double & 36.3 & 36.2 & 37.2 & 33.8 & 32.3 & 33.0 & 70 & 8.40 & 7.64 & 0.91 & 1.29 & 2.49 & -0.04 & 2.52 & 0.75 & 0.95 & 0.82 \\
\hline$P$ value $^{2}$ & & $\mathrm{NS}^{3}$ & NS & NS & 0.008 & 0.021 & NS & NS & NS & NS & NS & NS & NS & NS & NS & NS & 0.006 & 0.001 \\
\hline
\end{tabular}

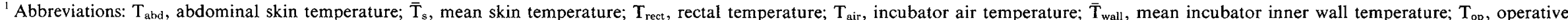

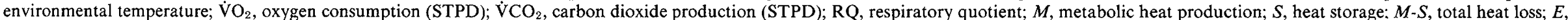
evaporative heat loss; $R$, radiant heat loss; $C$, convective (and conductive) heat loss $(M-S-E-R)$

${ }^{2}$ Two-tailed $t$ test for paired observations.

${ }^{3} \mathrm{NS}$ indicates $P \geq 0.05$ 
$33.0^{\circ} \mathrm{C}$ in both incubators. The electrical power used by the incubator heater was not significantly different. Subject 8 was studied on a day when the air-conditioning system was not functioning properly. The mean room temperature was high during both measurement periods, $29.4^{\circ} \mathrm{C}$ with the single-walled incubator and $27.4^{\circ} \mathrm{C}$ with the double-walled incubator. Consequently, very little heat output was required of the incubator, and the power consumption was only $3 \mathrm{~W}$ and $4 \mathrm{~W}$ in the single and double-walled incubators, respectively.

There were no significant differences in the mean oxygen consumption or carbon dioxide production rates or in the mean respiratory quotients. The mean $\dot{\mathrm{VO}}{ }_{2}$ was $7.95 \mathrm{ml} \cdot \mathrm{kg}^{-1} \cdot \mathrm{min}^{-1}$ (STPD) (S.D. 1.16) in the single-walled incubator and $8.40 \mathrm{ml}$. $\mathrm{kg}^{-1} \cdot \min ^{-1}$ (STPD) (S.D. 1.77) in the double-walled incubator The mean rate of insensible water loss was not different, $1.32 \mathrm{~g}$. $\mathrm{kg}^{-1} \cdot \mathrm{h}^{-1}$ with the single wall and $1.29 \mathrm{~g} \cdot \mathrm{kg}^{-1} \cdot \mathrm{h}^{-1}$ with the double wall.

The rates of metabolic heat production $(M)$, heat storage $(S)$, and total heat loss $(M-S)$ did not differ significantly between the single and double-walled incubators (Table 1). Evaporative heat loss was also not different. Radiant heat loss was significantly lower with the double wall, whereas convective heat loss was higher with the double wall. The mean coefficient of convective heat loss was $0.340 \mathrm{kcal} \cdot \mathrm{kg}^{-1} \cdot \mathrm{h}^{-1} \cdot{ }^{\circ} \mathrm{C}^{-1}$ in the single-walled incubator and $0.346 \mathrm{kcal} \cdot \mathrm{kg}^{-1} \cdot \mathrm{h}^{-1} \cdot{ }^{\circ} \mathrm{C}^{-1}$ with the double wall.

\section{DISCUSSION}

The methods of partitional calorimetry used in this study have been successfully applied in adult subjects $(14,29,30)$, but seldom attempted in newborn infants $(9,12,15)$. This technique allows estimation of the rate of body heat loss by each of the three major routes of heat exchange: evaporation, radiation, and convection. The exact numbers derived for radiant and convective heat loss are subject to error because of the assumptions that were required in order to perform the calculations described above. The most important of these assumptions was that the effective radiating surface area was $50 \%$ of the total body surface area. It is possible that the actual value was somewhat higher, but it is not likely to have been more than $60 \%$. If the effective radiating area had been assumed to be $60 \%$, the calculated radiant heat loss would have been increased by $20 \%$, and the convective heat loss, because it was smaller, would have been reduced by an even larger percentage.

Although the calculated partition between radiant and convective heat loss may not be exactly correct, the conclusion that the double wall decreased radiant heat loss and increased convective loss could be made solely on the basis of the temperature measurements. The skin-to-wall temperature gradient was smaller in the double-walled incubator $\left(3.9^{\circ} \mathrm{C}\right.$ versus $\left.4.6^{\circ} \mathrm{C}\right)$, whereas the skin-to-air gradient was larger $\left(2.4^{\circ} \mathrm{C}\right.$ versus $\left.1.5^{\circ} \mathrm{C}\right)$.

When the incubator heater was regulated by servocontrol to maintain abdominal skin temperature at $36.5^{\circ} \mathrm{C}$, the operative environmental temperature was identical, $33.0^{\circ} \mathrm{C}$, in the single and double-walled incubators. There was no reduction in oxygen consumption, insensible water loss, or metabolic heat production. The partition of nonevaporative heat loss was shifted toward less radiation and more convection with the double-walled incubator. Electrical power consumption was not reduced with the doublewalled incubator. It would appear that some of the energy used by the incubator to warm the air in the single-walled incubator was used instead to warm the inner walls of the double-walled incubator.

The applicability of these results to other incubators of this type is not known, because the air flow dynamics were altered by the withdrawal of air from the incubator for gas exchange measurement and by the presence of the Potter scale and the head hood.

Yeh et al. (32) measured respiratory gas exchange and insensible water loss in ten premature infants in single (Ohio Medical Products, Servo Care Incubator, Madison, WI) and double-walled (Ohio Intensive Care Incubator) incubators. Oxygen consumption, carbon dioxide production and insensible water loss were all significantly reduced in the double-walled incubator. Although the incubators were reportedly regulated by servocontrol to maintain abdominal skin temperature at $36.5^{\circ} \mathrm{C}$, the mean abdominal temperatures in both incubators were below $36.0^{\circ} \mathrm{C}$. Moreover, the abdominal skin temperatures were significantly lower in the single-walled incubator. The infants in the single-walled incubator were apparently below the thermoneutral zone and thus had a higher metabolic rate $\left(\mathrm{V}_{2}\right.$ and $\left.\dot{\mathrm{VCO}}_{2}\right)$ than in the double-walled incubator. The reduction in insensible water loss observed by Yeh et al. in the double-walled incubator is difficult to explain, unless it was caused by major differences in incubator humidity or air velocity, which were not measured (32).

Marks et al. (22) measured the oxygen consumption of ten premature infants in the same double-walled incubator (AirShields C-86 Isolette) used in our study. They reported a reduction in oxygen consumption in the double-walled incubator. The heater output was manually adjusted to maintain incubator air within the thermoneutral zone as taken from published tables. Air temperatures were the same in both incubators. One would not expect the same air temperature to be neutral for a given infant in both single and double-walled incubators. The neutral air temperature in the single-walled incubator should be higher because of the cooler walls. The subjects of Marks et al. were at cooler operative temperatures in the single-walled incubator; thus, it is possible that the infants were below the thermoneutral zone in the singlewalled incubator, accounting for their higher rate of oxygen consumption.

Our findings suggest that a double-walled incubator offers little benefit to the thermal economy of premature infants. When called upon to maintain the same abdominal skin temperature $\left(36.5^{\circ} \mathrm{C}\right)$, the single and double-walled incubators produced the same operative environmental temperature (mean $33.0^{\circ} \mathrm{C}$ ). Thus, the same thermal gradient from skin to environment was maintained despite the addition of the second, inner wall, which raised the inner wall temperature but lowered the incubator air temperature. Because the sum of nonevaporative heat losses is directly proportional to the gradient between skin and operative environmental temperatures (31), and because measured evaporative losses were not different, it is not surprising that total heat loss and metabolic heat production were the same in the two incubators. When servocontrolled in this fashion, the incubators allowed the infants to remain in thermal equilibrium at the same plane of heat production; neither incubator demanded excess heat production, because the total rate of body heat loss (i.e., net heat exchange with the environment) was the same.

This observation has important practical implications, because servocontrol is the method most often used to regulate incubator heat output in many nurseries. Moreover, double-walled incubators are more expensive to purchase. If skin temperature servocontrol is not used, then a double-walled incubator can be expected to reduce body heat loss compared to a single-walled incubator with the same air temperature (22) because radiant heat loss is reduced whereas evaporation and convection are unchanged. This difference could be easily overcome; however, by raising the air temperature in the single-walled incubator.

Although the double-walled incubator with its door closed offers no advantage when operated by skin temperature servocontrol in the usual nursery environment, the thermal insulation provided by the air between its walls might offer added protection against rapid fluctuations in ambient air temperature or the cold outside temperatures that are sometimes encountered during transport of small infants between hospitals. In such a situation, the inner wall surface of the single-walled incubator would cool faster, and the ability of the heater to compensate for increased radiant heat loss by raising air temperature would be exceeded sooner than with the double-walled incubator. It also seems possible that a double-walled incubator might allow a smaller fall in operative environmental temperature when the door is opened; the present study has provided no information that addresses this question. Although the double wall is presumably beneficial for incubators 
used to transport small infants between hospitals, it is apparently of limited value in modern air-conditioned nurseries where incubators are regulated by servocontrol to maintain a constant skin temperature.

It appears likely that the gradient between skin and operative environmental temperatures is the major determinant of body heat loss and, hence, of metabolic heat production of infants in incubators, provided heat and water loss by evaporation are constant. Servocontrolled incubators seem to maintain this thermal gradient at a uniform level despite the modest changes in inner wall temperature produced by inserting a second, inner layer of Plexiglas. Apart from the effects on water balance of changes in evaporation, the premature infant is metabolically indifferent to changes in the partitioning of body heat loss among the four routes (evaporation, radiation, convection, and conduction), as long as the sum of net exchanges of thermal energy by these four routes between the infant's body and the environment is unchanged.

\section{REFERENCES AND NOTES}

1. Bell, E. F., Gray J. C., Weinstein, M. R., and Oh, W.: The effects of thermal environment on heat balance and insensible water loss in low-birth-weight infants. J. Pediatr., 96: 452 (1980).

2. Bell, E. F., Weinstein, M. R., and Oh, W.: Heat balance in premature infants: Comparative effects of convectively heated incubator and radiant warmer, with and without plastic heat shield. J. Pediatr., 96: 460 (1980).

3. Bligh, J. and Johnson, K. G.: Glossary of terms for thermal physiology. J. Appl. Physiol., 35: 941 (1973).

4. Bohnenkamp, $H$. and Pasquay, W.: Untersuchungen zu den Grundlagen des Energie- und Stoffwechsels. III. Ein neuer Weg zur Bestimmung der für die Wärmestrahlung maßgebenden Oberfläche des Menschen. Die „mittlere Strahlungstemperatur" des Menschen und seiner Kleideroberfläche. Pflügers Arch. 228: 79 (1931).

5. Brück, K., Parmelee, A. H., Jr., and Brück, M.: Neutral temperature range and range of "thermal comfort" in premature infants. Biol. Neonate, 4: 32 (1962).

6. Burton, A. C.: Human calorimetry. II. The average temperature of the tissues of the body. J. Nutr., 9: 261 (1935).

7. Colin, J. and Houdas, Y.: Experimental determination of coefficient of heat exchanges by convection of human body. J. Appl. Physiol., 22: 31 (1967).

8. Darnall, R. A., Jr.: Insensible weight loss measurements in newborn infants: Possible overestimation with the Potter baby scale. J. Pediatr., 99: 794 (1981)

9. Day, R.: Respiratory metabolism in infancy and in childhood. XXVII. Regulation of body temperature of premature infants. Am. J. Dis. Child., 65: 376 (1943).

10. Doyle, L. W. and Sinclair, J. C.: Thermal effect on a Potter Baby Scale (abstract). Pediatr. Res., 15: 658 (1981).

11. Grayson, J. and Kuehn, L. A.: Heat transfer and heat loss. In: Lomax, P. and Schönbaum, E., (eds.): Body Temperature: Regulation, Drug Effects, and Therapeutic Implications, pp. 71-87 (Marcel Dekker, Inc., New York, 1979).

12. Hammarlund, K., Nilsson, G. E., Öberg, P. A., and Sedin, G.: Transepidermal water loss in newborn infants. V. Evaporation from the skin and heat exchange during the first hours of life. Acta Paediatr. Scand., 69: 385 (1980).

13. Hardy, J. D.: The radiation of heat from the human body. III. The human skin as a black-body radiator. J. Clin. Invest., 13: 615 (1934).

14. Hardy, J. D. and DuBois, E. F.: The technic of measuring radiation and convection. J. Nutr., 15: 461 (1938).

15. Hey, E.: The care of babies in incubators. In: Gairdner, D. and Hull, D., (eds.): Recent Advances in Paediatrics, ed. 4, pp. 171-215 (J. \& A. Churchill, London, 1971).

16. Hey, E. N. and Mount, L. E.: Heat losses from babies in incubators. Arch. Dis. Child., 42: 75 (1967).

17. Isenschmid: Die Bestimmung der Wasserbilanz am Krankenbett. Med. Klin. (Berlin), 14: 1128 (1918).

Copyright $(C) 1983$ International Pediatric Research Foundation, Inc. $0031-3998 / 83 / 1702-0135 \$ 02.00 / 0$
18. Karlberg, P.: The significance of depth of insertion of the thermometer for recording rectal temperatures. Acta Paediatr., 38: 359 (1949).

19. Lissauer, W.: Ueber Oberflächenmessungen an Säuglingen und ihre Bedeutung für den Nahrungsbedarf. Jahrb. Kinderheilk., 58: 392 (1903).

20. Lister, G., Hoffman, J. I. E., and Rudolph, A. M.: Oxygen uptake in infants and children: A simple method for measurement. Pediatrics, 53: 656 (1974).

21. Lusk, G.: The Elements of the Science of Nutrition, ed. 4, pp. 64-68 (W. B. Saunders Company, Philadelphia, 1928).

22. Marks, K. H., Lee, C. A., Bolan, C. D., Jr., and Maisels, M. J.: Oxygen consumption and temperature control of premature infants in a double-wall incubator. Pediatrics, 68: 93 (1981).

23. Meeh, K.: Oberflächenmessungen des menschlichen Körpers. Z. Biol., 15:425 (1879).

24. Mestyán, J., Járai, I., Bata, G., and Fekete, M.: The significance of facial skin temperature in the chemical heat regulation of premature infants. Biol. Neonate, 7: 243 (1964).

25. Ryser, G. and Jéquier, E.: Study by direct calorimetry of thermal balance on the first day of life. Eur. J. Clin. Invest., 2: 176 (1972).

26. Silverman, W. A., Sinclair, J. C., and Agate, F. J., Jr.: The oxygen cost of minor changes in heat balance of small newborn infants. Acta Paediatr. Scand., 55: 294 (1966).

27. Sinclair, J. C., Scopes, J. W., and Silverman, W. A.: Metabolic reference standards for the neonate. Pediatrics, 39: 724 (1967).

28. Wenger, C. B.: Heat of evaporation of sweat: Thermodynamic considerations. J. Appl. Physiol., 32: 456 (1972).

29. Winslow, C.-E. A., Herrington, L. P., and Gagge, A. P.: A new method of partitional calorimetry. Am. J. Physiol., 116: 641 (1936).

30. Winslow, C.-E. A., Herrington, L. P., and Gagge, A. P.: The determination of radiation and convection exchanges by partitional calorimetry. Am. J. Physiol., 116: 669 (1936).

31. Winslow, C.-E. A., Herrington, L. P., and Gagge, A. P.: Physiological reactions of the human body to varying environmental temperatures. Am. J. Physiol., 120: 1 (1937).

32. Yeh, T. F., Voora, S., Lilien, L. D., Matwynshyn, J., Srinivasan, G., and Pildes, R. S.: Oxygen consumption and insensible water loss in premature infants in single- versus double-walled incubators. J. Pediatr., 97: 967 (1980).

33. Incubator serial number AZ00694; power unit serial number AZ29300.

34. A 1-kg infant with $\dot{\mathrm{VO}}_{2}$ of 11.5 liter/day and $\dot{\mathrm{V}} \mathrm{CO}_{2}$ of 10.0 liter/day migh typically excrete $0.15 \mathrm{~g}$ of nitrogen per day in the urine. The contribution to $\mathrm{VO}_{2}$ and $\dot{\mathrm{V} C O} \mathrm{C}_{2}$ from protein metabolism would be 0.9 and 0.7 liter/day, respectively (21). The nonprotein $\dot{\mathrm{V}} \mathrm{O}_{2}$ and $\dot{\mathrm{VCO}}_{2}$ would be 10.6 and 9.3 liter/ day, respectively, and the nonprotein $\mathrm{RQ}$ would be 0.88 . The corresponding factor for converting $\mathrm{VO}_{2}$ to heat production is $4.899 \mathrm{kcal} /$ liter (21), so the nonprotein heat production would be $51.9 \mathrm{kcal} /$ day $(4.899 \times 10.6)$. The heat derived from protein metabolism would be $4.0 \mathrm{kcal} / \mathrm{day}(21)$, yielding a tota heat production of $55.9 \mathrm{kcal} / \mathrm{day}$ or $2.33 \mathrm{kcal} / \mathrm{h}$. For comparison, if the urinary nitrogen is not collected and the contribution of protein metabolism to hea production is neglected, the measured RQ 0.87 would be used to determine the conversion factor, $4.887 \mathrm{kcal} / \mathrm{liter}$. The calculated heat production would be $56.2 \mathrm{kcal} /$ day or $2.34 \mathrm{kcal} / \mathrm{h}$; thus, the error produced by neglecting protein metabolism would be approximately $0.5 \%$.

35. The authors thank Dr. Carl V. Gisolfi for performing Haldane analyses of calibration gas mixtures, Christian B. Andreasen for advice and support, Kerry S. Ostlund for preparing the manuscript, and Drs. Samuel J. Fomon and William A. Silverman for critical review.

36. This paper was presented in part at the Young Investigator Award Symposium of the Section on Perinatal Pediatrics, American Academy of Pediatrics, on November 1, 1981, in New Orleans.

37. This research was supported by Basil O'Connor Starter Research Grant No. 5268 from the March of Dimes Birth Defects Foundation, by Biomedical Research Support Grant RR 05372 from the Biomedical Research Support Branch, Division of Research Facilities and Resources, National Institutes of Health, and by a grant-in-aid from Air-Shields, Inc.

38. Received for publication February 24, 1982

39. Accepted for publication June 15, 1982

40. Requests for reprints should be addressed to: Edward F. Bell, M.D., Department of Pediatrics, University of Iowa, Iowa City, IA 52242. 